Review Article

\title{
Natural Modulators of Endosomal Toll-Like Receptor-Mediated Psoriatic Skin Inflammation
}

\author{
Chao-Yang Lai, ${ }^{1}$ Yu-Wen Su, ${ }^{1}$ Kuo-I Lin, ${ }^{2}$ Li-Chung Hsu, ${ }^{3}$ and Tsung-Hsien Chuang ${ }^{1,4}$ \\ ${ }^{1}$ Immunology Research Center, National Health Research Institutes, Miaoli 35053, Taiwan \\ ${ }^{2}$ Genomics Research Center, Academia Sinica, Taipei 115, Taiwan \\ ${ }^{3}$ Institute of Molecular Medicine, College of Medicine, National Taiwan University, Taipei 10002, Taiwan \\ ${ }^{4}$ Program in Environmental and Occupational Medicine, Kaohsiung Medical University, Kaohsiung 807, Taiwan
}

Correspondence should be addressed to Tsung-Hsien Chuang; thchuang@nhri.org.tw

Received 19 January 2017; Accepted 25 July 2017; Published 13 August 2017

Academic Editor: Pushpa Hegde

Copyright @ 2017 Chao-Yang Lai et al. This is an open access article distributed under the Creative Commons Attribution License, which permits unrestricted use, distribution, and reproduction in any medium, provided the original work is properly cited.

Psoriasis is a chronic inflammatory autoimmune disease that can be initiated by excessive activation of endosomal toll-like receptors (TLRs), particularly TLR7, TLR8, and TLR9. Therefore, inhibitors of endosomal TLR activation are being investigated for their ability to treat this disease. The currently approved biological drugs adalimumab, etanercept, infliximab, ustekinumab, ixekizumab, and secukizumab are antibodies against effector cytokines that participate in the initiation and development of psoriasis. Several immune modulatory oligonucleotides and small molecular weight compounds, including IMO-3100, IMO-8400, and CPG-52364, that block the interaction between endosomal TLRs and their ligands are under clinical investigation for their effectiveness in the treatment of psoriasis. In addition, several chemical compounds, including AS-2444697, PF-05387252, PF-05388169, PF-06650833, ML120B, and PHA-408, can inhibit TLR signaling. Although these compounds have demonstrated anti-inflammatory activity in animal models, their therapeutic potential for the treatment of psoriasis has not yet been tested. Recent studies demonstrated that natural compounds derived from plants, fungi, and bacteria, including mustard seed, Antrodia cinnamomea extract, curcumin, resveratrol, thiostrepton, azithromycin, and andrographolide, inhibited psoriasis-like inflammation induced by the TLR7 agonist imiquimod in animal models. These natural modulators employ different mechanisms to inhibit endosomal TLR activation and are administered via different routes. Therefore, they represent candidate psoriasis drugs and might lead to the development of new treatment options.

\section{Introduction}

Psoriasis is a common immune-mediated chronic inflammatory skin disease that affects the quality of life of $2 \%-3 \%$ of the global population. Psoriasis is typically associated with red, scaly, raised plaques resulting from a marked thickening of the epidermis induced by enhanced keratinocyte proliferation, leukocyte infiltrates in the epidermis and dermis, and inflammation [1-5]. Leukocyte infiltrates in psoriatic lesions primarily comprise dendritic cells (DCs), macrophages, neutrophils, and T cells. DCs generate multiple proinflammatory cytokines, including TNF- $\alpha$, IL- $1 \beta$, IL- 6 , and IL-23, that promote the development of psoriasis. TNF- $\alpha$ is a potent proinflammatory stimulus that promotes IL- 23 production in DCs. IL-1 $\beta$ can activate IL-17 secretion from Th17 cells.
IL-6 protects cutaneous T cells from Treg suppression and promotes Th17 participation in inflammation. Together, these immune cells and cytokines promote the inflammatory responses that underlie the development of psoriatic lesions.

Psoriasis can result from an interplay between genetic factors and external factors, including microbial infections, skin injuries, immune disorders, environmental influences, weather, and stress [6-15]. Nevertheless, the molecular mechanisms underlying the pathogenesis of this disease are not yet fully understood. TLRs are a family of pattern recognition receptors (PPRs) that localize to the cell surface or intracellular vesicles and are responsible for recognizing pathogen-associated molecular patterns (PAMPs) associated with microbes and danger-associated molecular patterns (DAMPs) released from dead cells in damaged tissues. A 
group of intracellular TLRs referred to as endosomal TLRs contributes to the pathogenesis and development of psoriasis by sensing endogenous DNA and RNA released from dead cells. In this review, we discuss current knowledge on the mechanism underlying endosomal TLR activation and the link between endosomal TLR activation and the pathogenesis of psoriasis. This mechanism can inform the development of therapeutics for psoriasis that target endosomal TLRs. Synthetic antagonists of endosomal TLRs are currently being developed. Natural products from plants, fungi, and bacteria are promising candidate drugs in this context because of their diverse structures and bioactivities. Many natural compounds have demonstrated acceptable safety profiles and immunomodulatory activity $[16,17]$. We also discuss recently identified natural compounds that inhibit endosomal TLRs and reduce psoriatic inflammation via different mechanisms.

\section{Toll-Like Receptors}

The innate immune system is the first line of host defense to microbial infections. Innate immune cells use a diverse variety of PPRs including TLRs, nucleotide-binding oligomerization domain- (NOD-) like receptors (NLRs), C-type lectin-like receptors (CLRs), retinoic acid-inducible gene(RIG-) I-like receptors (RLRs), and intracellular DNA sensor proteins to detect a wide variety of microbial PAMPs that initiate intermediate innate immune responses and lead to the development of adaptive immune responses [18-29]. Of them, TLRs are the most well-characterized PRRs. Thirteen TLRs have been identified in mammals, and ten of these (TLR1-10) are expressed in humans [30-35]. Human TLRs are strongly expressed in multiple types of immune cells, including DCs, macrophages, monocytes, natural killer cells, B cells, and $\mathrm{T}$ cells. They are also expressed in other cell types, including keratinocytes, chondrocytes, endothelial cells, and fibroblasts. Human TLRs are type I transmembrane receptors that feature an extracellular domain, a transmembrane region, and a highly conserved cytoplasmic region. The extracellular domain consists of multiple leucine-rich repeats (LRRs). The cytosolic region contains a Toll/interleukin-1 receptor (TIR) domain that mediates protein-protein interactions with the TIR domains of MyD88 adaptor protein family members, and these interactions initiate downstream intracellular signaling pathways [35-41].

TLRs interact with a diverse variety of microbial PAMPs via their extracellular domain (Figure 1). TLR2 recognizes a broad range of microbial components, including peptidoglycan, lipoteichoic acids, lipoproteins, lipoarabinomannan, glycophosphatidylinositol anchors, prions, and zymosan [42-48]. TLR2 and TLR6 form a complex that selectively recognizes mycoplasma macrophage-activating lipopeptide 2 , whereas a heterodimer composed of TLR2 and TLR1 selectively recognizes bacterial lipoproteins and triacyl lipopeptides. Natural ligands of TLR10 have not yet been identified [49-51]. TLR4 is the primary receptor responsible for recognizing lipopolysaccharides on the outer membrane of gram-negative bacteria, and TLR5 recognizes flagellin, a component of bacterial flagella $[52,53]$. The binding of members of the TLR3, TLR7, TLR8, and TLR9 subfamilies to their ligands is mediated by the recognition of nucleic acid-derived structures. TLR3 recognizes double-stranded RNA (dsRNA) generated during viral replication in infected cells [54]. TLR7 and TLR8 recognize single-stranded RNA viruses such as vesicular stomatitis virus and the influenza virus $[55,56]$. TLR9 is required for the response to microbial unmethylated CpG DNA [57, 58]. Most CpG sites in mammalian cells are methylated, whereas microbial CpG sites are typically unmethylated; therefore, unmethylated $\mathrm{CpG}$ DNA is a microbial PAMP $[59,60]$. In addition, TLRs recognize a wide variety of DAMPs released from dead cells at inflammatory sites (Figure 1). DAMPs recognized by TLRs include cellular components and stress-induced gene products such as extracellular matrix components, extracellular proteins, intracellular proteins, and nucleic acids [61, 62]. TLR2 recognizes heat shock proteins (HSPs), Gp96, biglycan, hyaluronic acid, hyaluronan, high-mobility group box 1 (HMGB1), versican, and monosodium urate crystal [63-71]. TLR4 recognizes HSPs, Gp96, HMGB1, oxidized phospholipids, heparan sulfate, fibrinogen, fibronectin, tenascin-C, hyaluronic acid, and hyaluronan [64, 69-79]. TLR3, TLR7, TLR8, and TLR9 are activated by host RNA and host DNA from necrotic cells [80-83].

Upon activation by PAMPs or DAMPs, TLR monomers dimerize, and their cytosolic domains subsequently recruit adaptor proteins from the MyD88 family (MyD88, TRIF/ TICAM-1, TIRAP/Mal, TIRP/TRAM, and SRAM), thereby initiating downstream signaling pathways [84] (Figure 1). With the exception of TLR3, which signals via a TRIFdependent signaling pathway, all TLRs signal via a MyD88dependent pathway. In the MyD88-dependent pathway, a MyD88/IRAK1/IRAK4/TRAF6 complex activates TAK1, thereby promoting the activation of several transcription factors, including NF- $\kappa \mathrm{B}$ and AP-1. TLR3 and TLR4 recruit TRIF to activate NF- $\kappa$ B, AP- 1 , and IRF3/7. NF- $\kappa$ B and AP1 activation involves TRAF6 and RIP, and IRF3/7 activation is mediated by a TBK1-IKKe/IKKi complex (Figure 1). These transcription factors are key regulators of the expression of adhesion and costimulatory molecules and the production of various inflammatory cytokines required for the maturation, differentiation, and proliferation of DCs, natural killer cells, and cytotoxic T cells [41, 85-88].

\section{Endosomal Toll-Like Receptors}

The ten human TLRs are divided into three phylogenetic subfamilies. The first subfamily comprises TLR1, TLR2, TLR6, and TLR10. The second subfamily comprises TLR4 and TLR5, and the third subfamily comprises TLR3, TLR7, TLR8, and TLR9 (Figure 2(a)). TLR1, TLR2, TLR4, TLR5, and TLR6 are expressed on the cell surface. In contrast, TLR3, TLR7, TLR8, and TLR9 localize to the endoplasmic reticulum and are trafficked to the endosomal/lysosomal compartment where they initiate cellular responses upon their activation by PAMPs and DAMPs. Therefore, these four TLRs are referred to as endosomal TLRs $[89,90]$. In addition to their unique mechanism of ligand recognition, 


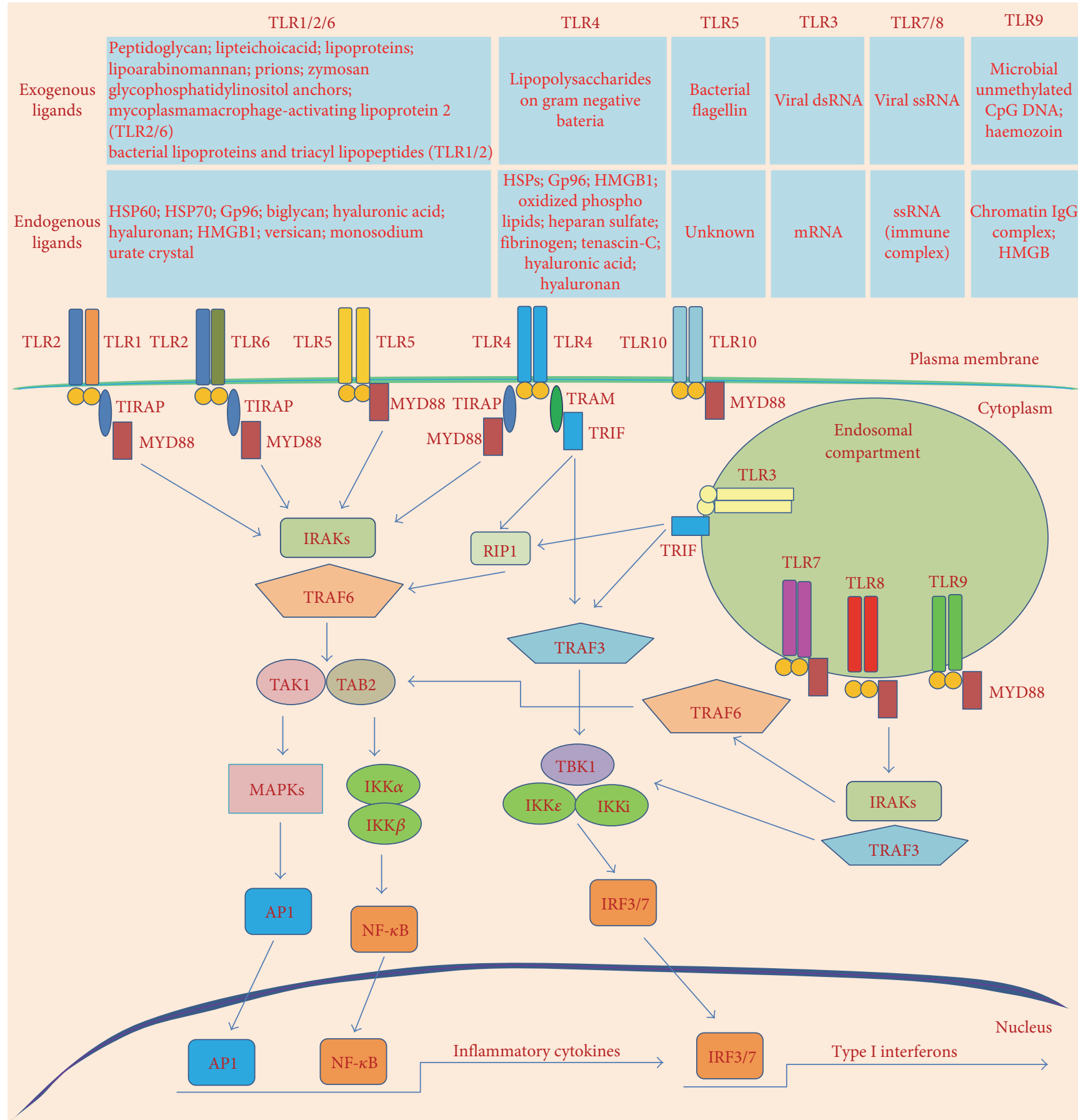

FIgURE 1: TLR ligands and signaling pathways. TLRs localize to the cell surface and to intracellular vesicles such as endosomes where they respond to their exogenous and endogenous ligands as shown. The TLRs utilize adaptor proteins of the MyD88 family, including MyD88, TRIF, TIRAP, and TRAM, to initiate downstream signaling pathways that induce the activation of various transcription factors, including NF- $\kappa$ B, AP-1, and IRF3/7, and the production of inflammatory cytokines and type I interferons.

the four endosomal TLRs are also distinct from other TLRs with respect to protein length. Specifically, TLR7, TLR8, and TLR9 are composed of more than 1000 amino residues (Figure 2(a)), and their extracellular domain is longer than that of other TLRs. Most TLRs contains 19-25 LRRs arranged in a horseshoe-shaped solenoid structure that mediates ligand binding. TLR7, TLR8, and TLR9 have 25 LRRs and a unique undefined region/Z-loop between
LRR14 and LRR15 (Figure 2(b)). Previous studies have shown that mouse and rat TLR8 has low activity levels and can only be activated by agonists in the presence of PolyTODN. The lack of a five-amino-acid motif in the undefined region/Z-loop is proposed to account for the weak activity of these two TLR8 homologues, suggesting that the undefined region/Z-loop plays a role in the activation of TLR7, TLR8, and TLR9 [91, 92]. 


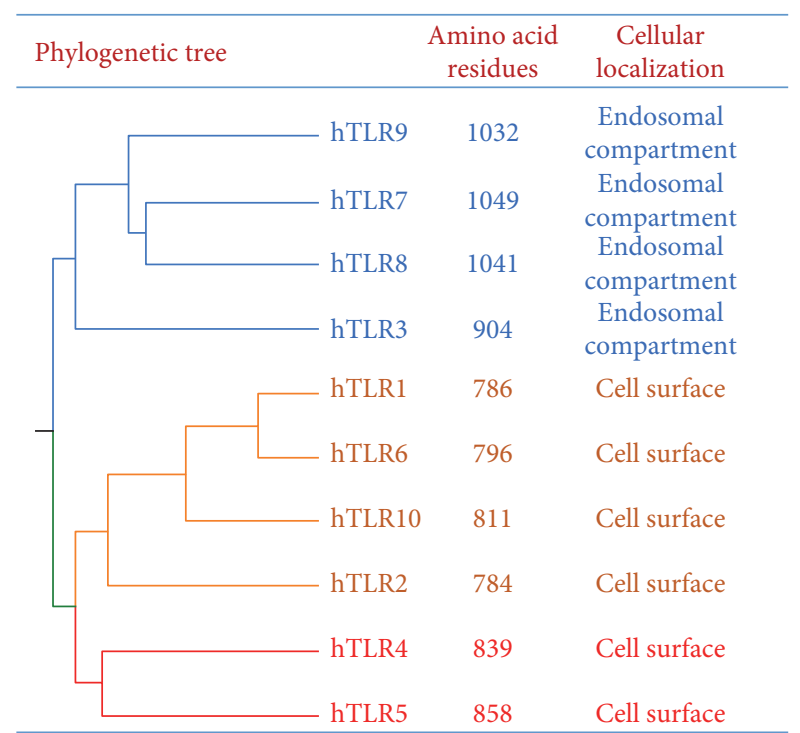

(a)

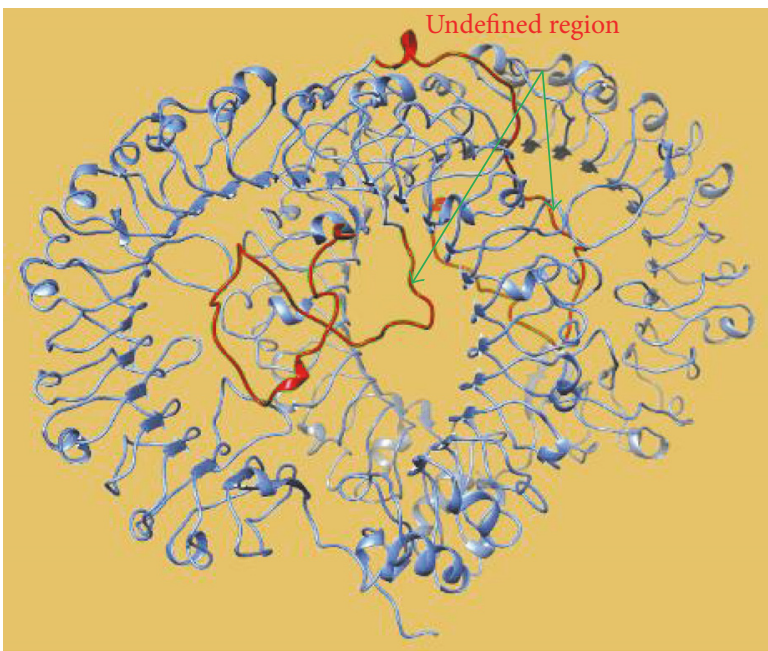

(b)

FIgURE 2: Subfamilies and the extracellular structure of human TLRs. (a) Human TLRs are divided into three phylogenetic subfamilies shown with different colors. The number and cellular location of amino acid residues are shown in the middle and right columns, respectively. (b) Computational modeling of the ectodomain structure of dimerized TLR7. Blue color shows the horseshoe-shaped solenoid structure of TLR ectodomain. Arrowheads indicate undefined regions (red color).

Endosomal TLRs must be trafficked from the endoplasmic reticulum to specific cellular locations in order to be activated. The intracellular trafficking of endosomal TLRs is regulated by accessory proteins such as UNC-93 homolog B1 (UNC93B1) and specific adaptor proteins (APs). UNC93B1 directly interacts with endosomal TLRs in the endoplasmic reticulum, facilitates their transport to the Golgi apparatus via coat protein complex II (COPII) vesicles, and remains associated with them in endosomes. AP1 and AP2 are required for UNC93B1-mediated endosomal TLR trafficking. AP3 facilitates TLR9 trafficking from endosomes to lysosome-related organelles (LROs). In contrast to the effects of TLR9 activation at endosomes, TLR9 activation at LROs induces the production of type I interferons rather than proinflammatory cytokines [93-95].

After reaching the endosomal compartment, TLRs are cleaved by specific proteases, including asparagine endopeptidase (AEP) and cathepsins such as cathepsin B, cathepsin $\mathrm{H}$, cathepsin K, cathepsin L, and cathepsin S [96-98]. For example, TLR9 is cleaved at its undefined region/Z-loop in endosomes, and this cleavage is a prerequisite for its activation. Interestingly, following proteolytic cleavage, the $\mathrm{N}$ terminal and C-terminal portions remain associated with one another, and this association is required for protein function [98-102]. This raises the question of what the role of proteolytic cleavage in TLR activation is. Recent studies have shown that the cleaved and uncleaved receptors bind with equal affinity to their ligand [101, 103]. Nevertheless, ligand-induced TLR dimerization requires proteolytic cleavage to relieve steric hindrance at the undefined region/Z-loop. This finding is consistent with the observation that endosomal acidification is required for endosomal TLR activation, as an acidic $\mathrm{pH}$ is required for the activation of cathepsins and most endosomal and lysosomal proteases [99-101].

\section{The Role of Endosomal Toll-Like Receptors in the Pathogenesis of Psoriasis}

In recent years, significant progress has been made in our understanding of the molecular mechanisms underlying the pathogenesis of psoriasis and the role of endosomal TLRs in this process. As shown in Figure 3, in the initiation phase, external triggers such as microbial infections and skin injuries induce the release of the antimicrobial peptide LL37 from keratinocytes and the release of self-DNA and self-RNA from dying cells to activate endosomal TLRs [104-106]. These TLRs can typically distinguish pathogen-derived nucleic acids from self-derived nucleic acids. Nucleic acids derived from viruses during cytosolic replication can be transported into endosomes during the process of autophagy where they activate endosomal TLRs. However, the localization of endosomal TLRs to intracellular compartments prevents their activation by self-nucleic acids under physiological conditions, because self-nucleic acids from dead cells in damaged tissues are unable to passively enter other cells and endosomes $[107,108]$. Nevertheless, tolerance to self-nucleic acids can be evaded under some pathological conditions. For example, the antimicrobial peptide LL37 is upregulated and delivered to inflammatory sites in psoriatic skin where it forms complexes with self-nucleic acids to facilitate their entry into DCs and the subsequent activation of endosomal TLRs. These events render nonstimulatory self-nucleic acids into potent immune stimuli [104-106, 109, 110].

Endosomal TLRs are differentially expressed in different subsets of DCs. Plasmacytoid DCs (pDCs) express TLR7 


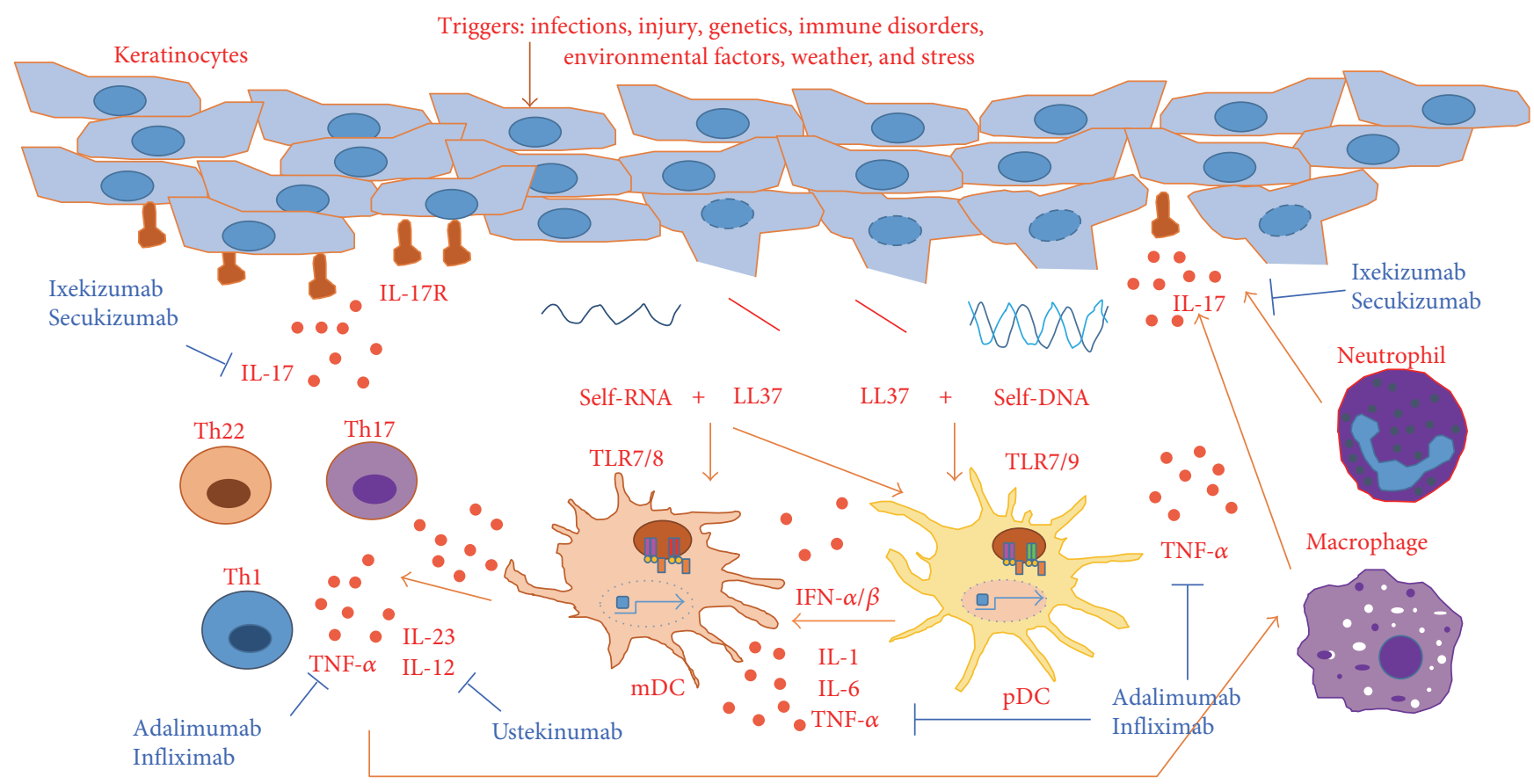

FIGURE 3: The role of endosomal TLRs in the development of psoriasis and the mechanism of action of biological drugs. Endosomal TLRs in plasmacytoid dendritic cells (pDCs) and myeloid dendritic cells (mDCs) can be triggered by self-DNA and self-RNA that forms complexes with LL37 upon its release from necrotic cells. Cytokines released by DCs further drive T cell-mediated inflammation by activating cytokines that promote leukocyte recruitment and keratinocyte activation and proliferation. Blue font: biological drugs inhibit effector cytokines in psoriatic inflammation.

and TLR9, and myeloid DCs (mDCs) express TLR7 and TLR8 [111]. Thus, LL37/RNA and LL37/DNA complexes can trigger the production of various proinflammatory cytokines, including TNF- $\alpha$, IL-1, and IL-6, as well as type I interferons in pDCs, by activating TLR7 and TLR9. Cytokines produced by pDCs in turn promote the activation of mDCs. In addition, LL37/RNA complexes can directly activate mDCs via TLR7 and TLR8, thereby inducing the production of IL-12 and IL-23 in mDCs at psoriatic inflammatory sites (Figure 3). These cytokines activate T cells into Th1, Th22, and Th17 cells, thereby further activating cytokines that promote keratinocyte activation and proliferation and the recruitment of inflammatory cells such as neutrophils and macrophages to psoriatic lesions [112, 113]. Together, these events result in chronic cutaneous inflammation.

\section{Evidence for the Involvement of Endosomal TLRs in Psoriatic Inflammation}

The involvement of endosomal TLRs in the pathogenesis of psoriasis is supported by studies of imiquimod in mouse models of psoriasis. Imiquimod is a small molecular weight agonist of TLR7. Aldara ${ }^{\mathrm{TM}}$ is a $5 \%$ imiquimod cream approved for the treatment of genital warts and superficial basal cell carcinoma. In mouse models, consecutive topical application of Aldara cream to the ear or shaved back skin causes inflammation, and the responses to imiquimod in mice closely resemble symptoms of human psoriasis, including skin thickening and erythema. Aldara not only causes phenotypic changes consistent with psoriasis but it also induces leukocyte infiltration and activation of the IL-23/ Th17 axis, suggesting that the mechanism of imiquimodinduced pathogenesis is similar to the pathogenesis of human psoriasis [114-116]. Consistent with these findings, there have been reports of psoriasis associated with the clinical application of imiquimod in patients with basal cell carcinoma or actinic keratosis with or without a history of psoriasis [116-118].

Direct evidence that endosomal TLRs are potential therapeutic targets of psoriasis treatment stems from clinical investigation of TLR antagonists. In a phase 2 clinical trial in patients with moderate to severe psoriasis, immune modulatory oligonucleotide- (IMO-) 3100, an antagonist of TLR7 and TLR9, was associated with a reduction in Psoriasis Area Severity Index (PASI) score. In an animal model of psoriasis established by intradermal injection of IL-23 in the dorsum, IMO-3100 inhibited epidermal hyperplasia. IL-23 injection altered the expression of more than 5000 genes and upregulated the expression of genes associated with IL-17 signaling [119]. Treatment with IMO-3100 modulated the expression of 1900 of genes and downregulated the expression of IL17-regulated genes. IMO-8400 is a second generation IMO that antagonizes TLR7, TLR8, and TLR9. Similar to IMO3100, IMO-8400 inhibited symptoms of psoriasis; however, IMO-8400 had a broader effect on the expression of IL-23induced genes. In a phase $2 \mathrm{a}$ clinical trial evaluating the safety and efficacy of IMO-8400 compared with placebo in patients with moderate to severe plaque psoriasis, IMO-8400 did not cause any serious or severe adverse effects and it demonstrated clinical improvements. PASI-50 with IMO-8400 was 
TABLE 1: Inhibitors for endosomal TLR-mediated inflammation.

\begin{tabular}{|c|c|c|}
\hline Inhibitor & Natural/synthetic & Target and mechanism of action \\
\hline IMO-3100 & Synthetic & Antagonist of TLRs \\
\hline IMO-8400 & Synthetic & Antagonist of TLRs \\
\hline IRS-954 & Synthetic & Antagonist of TLRs \\
\hline DV117 & Synthetic & Antagonist of TLRs \\
\hline INH-ODN-24888 & Synthetic & Antagonist of TLRs \\
\hline CPG-52364 & Synthetic & Antagonist of TLRs \\
\hline Chloroquine & Synthetic (quinine derivative) & Inhibits endosomal acidification or sequester TLR ligands \\
\hline Hydrochloroquin & Synthetic (quinine derivative) & Inhibits endosomal acidification or sequester TLR ligands \\
\hline Quinacrine & Synthetic (quinine derivative) & Inhibits endosomal acidification or sequester TLR ligands \\
\hline Bortezomib & Synthetic & Inhibits TLR trafficking \\
\hline SM934 & Synthetic & Promotes downregulation of TLRs \\
\hline ST-2825 & Synthetic & MyD88 inhibitor \\
\hline AS-2444697 & Synthetic & IRAK4 inhibitor \\
\hline PF-05387252 & Synthetic & IRAK4 inhibitor \\
\hline PF-05388169 & Synthetic & IRAK4 inhibitor \\
\hline PF-06650833 & Synthetic & IRAK4 inhibitor \\
\hline ML120B & Synthetic & IKK2 inhibitor \\
\hline PHA-408 & Synthetic & IKK2 inhibitor \\
\hline Mustard seed & Natural (mustard plant product) & Inhibit NF- $\kappa \mathrm{B}$ activation and cytokine expression \\
\hline Antrodia cinnamomea extract & Natural (A. cinnamomea product) & Inhibit cytokine expression \\
\hline Curcumin & Natural (grapes product) & Inhibit NF- $\kappa \mathrm{B}$ activation and cytokine expression \\
\hline Resveratrol & Natural (grapes product) & Inhibit NF- $\kappa \mathrm{B}$ activation and cytokine expression \\
\hline Thiostrepton & Natural (Streptomyces product) & Inhibits endosomal acidification and proteasomal activity \\
\hline Azithromycin & Natural (Streptomyces product) & Inhibits endosomal acidification and proteasomal activity \\
\hline Andrographolide & Natural (A. paniculata product) & Promotes downregulation of myD88 \\
\hline
\end{tabular}

$38 \%$ compared with $1 \%$ with placebo, and PASI-75 and PASI-90 with IMO-8400 were $17 \%$ and $2 \%$, respectively, compared with $0 \%$ with placebo $[119,120]$. These findings support the hypothesis that blocking endosomal TLR activation is a promising therapeutic approach for the treatment of psoriasis.

\section{Strategies for Blocking Endosomal TLR-Mediated Inflammation}

The design of strategies to block inflammatory responses elicited by the activation of distinct endosomal TLRs can be based on their unique functions and signaling mechanisms. These strategies are (1) neutralizing cytokines that mediate the effects of endosomal TLRs, (2) blocking TLR ligand interactions using TLR antagonists, (3) blocking TLR ligand interactions by sequestering TLR ligands, (4) blocking TLR activation by inhibiting proteasomal activity and endosomal acidification, (5) downregulating TLRs and their downstream signaling molecules, and (6) inhibiting signal transduction downstream of endosomal TLR activation. The feasibility of these strategies to treat psoriasis and other autoimmune diseases, including rheumatoid arthritis (RA) and systemic lupus erythematosus (SLE), has been demonstrated by the action mechanisms of the biological drugs and synthetic compounds (shown in Figure 3 and Table 1) that are currently being used or investigated.

6.1. Biological Drugs That Neutralize Effector Cytokines. Several biological drugs targeting cytokines that can be directly or indirectly generated by the activation of endosomal TLRs have been approved by FDA for the treatment of psoriasis. These biological drugs can be divided into three classes: TNF- $\alpha$ antagonists, IL-12/IL-23 inhibitors, and IL-17A inhibitors. The TNF- $\alpha$ antagonists adalimumab, etanercept, and infliximab have demonstrated strong efficacy in the treatment of moderate to severe psoriasis. Adalimumab is a fully humanized monoclonal antibody [121-123]. Etanercept is a recombinant fusion protein containing a TNF- $\alpha$ receptor ligandbinding domain and a human IgG Fc domain [124-126]. Infliximab is a chimeric monoclonal antibody [127-129]. TNF- $\alpha$ antagonists reduce inflammatory responses at psoriatic sites and downregulate the differentiation and function of Th17 cells. These findings suggest that TNF- $\alpha$ functions upstream of the IL-23/Th17 axis. Ustekinumab is a member of the class of psoriasis drugs that target IL-12/IL-23. It is a humanized monoclonal antibody that neutralizes the p40 subunit common to both IL-12 and IL-23, thereby preventing the binding of these cytokines to their receptors and the subsequent initiation of Th1- and Th17-mediated signaling pathways [130, 131]. Ustekinumab demonstrated a superior 
clinical effect to etanercept, suggesting that IL-23 plays a key role in the pathogenesis of psoriasis [132, 133]. The human monoclonal antibodies ixekizumab and secukizumab are members of the class of psoriasis drugs that target IL-17A. Multiple studies have shown that ixekizumab and secukizumab inhibit the expression of a wide variety of genes associated with Th17- and Th1-mediated inflammatory responses. Although these biological drugs have demonstrated efficacy in the treatment of psoriasis, their use is limited by their high cost and the fact that they must be administered by injection. Therefore, synthetic chemical drugs and natural inhibitors continue to be investigated and developed.

6.2. TLR Antagonists. IMO-3100 and IMO-8400 (discussed in Section 5) bind to endosomal TLRs, thereby preventing the interaction of endosomal TLRs with their agonists. Other immune inhibitory oligonucleotides that directly interact with TLR7 and TLR9, including IRS-954, DV117, and INH-ODN-24888, have also been developed [134-137]. The binding of these compounds to endosomal TLRs blocks their access to the agonists that trigger their activation. Although their therapeutic potential for the treatment of psoriasis has not yet been evaluated, these compounds have demonstrated immune inhibitory effects in preclinical and clinical SLE trials. CPG-52364 is another endosomal TLR inhibitor that blocks ligand-induced activation of TLR7, TLR8, and TLR9. Structurally distinct from other inhibitory oligonucleotides, CPG-52364 is a derivative of the small molecular weight chemical compound quinazoline. CPG52364 has been reported to be well tolerated in clinical trials evaluating its effect in the treatment of several inflammatory autoimmune diseases, including psoriasis, RA, and SLE [137-139].

6.3. Compounds That Inhibit Endosomal Acidification, Proteasomal Activity, and Sequestering TLR Ligands. The antimalarial drugs chloroquine, hydroxychloroquine, and quinacrine are derivatives of quinine, a natural alkaloid isolated from the South American cinchona bark tree. Although they are primarily used to treat malaria, these drugs have long been used for treating skin diseases and reducing inflammation in RA and SLE. More recent studies demonstrated that these compounds function as inhibitors of TLR7, TLR8, and TLR9 [140, 141]. They are weak bases; therefore, their ability to inhibit endosomal TLR activation has been attributed to their ability to inhibit endosomal acidification. These antimalarial compounds have also been shown to directly interact with nucleic acid-based TLR ligands, thereby sequestering these ligands and preventing them from binding to endosomal TLRs. Bortezomib (Velcade) is one example of a drug that targets proteasomal activity. Bortezomib is a proteasome inhibitor approved for the treatment of multiple myeloma, and it has demonstrated inhibitory effects in several autoimmune disorders, including psoriasis, RA, and SLE, in animal models [142-144]. In addition, bortezomib has been shown to suppress the trafficking of TLR9 to endolysosomes, inhibit TLR9 activation, and reduce lupus- and psoriasis-associated inflammation $[145,146]$.
6.4. Compounds That Downregulate Endosomal TLRs and Inhibit TLR Signaling. Other small molecular weight chemical compounds that inhibit TLR signaling and TLRmediated inflammatory responses in autoimmune diseases include SM934, ST-2825, IRAK4 inhibitors, and IKK2 inhibitors. SM934 ( $\beta$-aminoarteether maleate), a derivative of artemisinin, possesses potent antiproliferative and antiinflammatory properties. In a preclinical study, SM934 provided a significant protective effect in a mouse model of SLE. SM934 inhibits TLR activation by promoting the downregulation of TLR7, TLR9, and MyD88 mRNA expression and the inhibition of NF- $\kappa$ B phosphorylation [147-149]. Other compounds that block NF- $\kappa$ B activation and cytokine production by targeting molecules associated with TLR signaling have also been developed. For example, the peptide mimetic ST-2825 targets MyD88. ST-2825 interferes with MyD88-mediated recruitment of IRAK1 and IRAK4 to the TLR signalsome, thereby inhibiting TLR-mediated inflammatory responses. This compound has been shown to inhibit TLR9 activation and block the production of autoantibodies in B cells in SLE patients $[150,151]$. AS-2444697, PF05387252, PF-05388169, and PF-06650833 target the kinase activity of IRAK4 and have been investigated in preclinical or clinical studies for the treatment of multiple inflammatory and autoimmune diseases, including gout, sepsis, AR, and SLE $[152,153]$. IKK2 is a subunit of I $\kappa$ B kinase, a protein that controls NF- $\kappa \mathrm{B}$ activation and the production of TLRinduced inflammatory cytokines. The chemical compounds ML120B and PHA-408 inhibit IKK2 kinase activity and have exhibited anti-inflammatory effects in an animal model of arthritis [154-156].

\section{Natural Inhibitors of Endosomal TLR-Mediated Psoriatic Inflammation}

Many natural compounds derived from bacteria, fungi, and plants have long been known to exhibit immunomodulatory activity and have been used for the treatment of inflammation-related disorders [16, 17]. For example, retinoids, vitamin $\mathrm{D}$, and their corresponding analogs are used in topical treatments for psoriasis $[157,158]$. These compounds bind to their endogenous cellular receptors, thereby initiating the transcription of genes that suppress inflammation and inhibit cell proliferation. In addition, the following plant extracts and natural compounds have been reported to inhibit endosomal TLR-mediated psoriatic inflammation in animal models via different mechanism of actions shown in Table 1. These natural products have therapeutic potential in the treatment of psoriasis.

7.1. Mustard Seed. Mustard seed from mustard plant is a popular food seasoning worldwide, especially in Japan, India, and China. Mustard seed possesses several biological effects, including anti-inflammatory, antioxidant, and antitumor effects. These effects are mediated by multiple active components, including erucic acid, isothiocyanate, phenols, and phytin [159]. In mice, a diet supplemented with 5\% mustard seed for three weeks attenuated imiquimod-induced psoriasis-like inflammation. Mustard seed inhibited the 
infiltration of various types of leukocytes, including DCs, macrophages, and $\mathrm{T}$ cells, into psoriatic lesions. In addition, PASI score significantly decreased in mustard seed-fed mice compared with control mice. Furthermore, NF- $\kappa \mathrm{B}$, IFN- $\alpha$, IL-17, and IL-22 levels decreased in the psoriatic lesions of mustard seed-fed mice compared with control mice [160]. However, the specific component mediating this effect and its molecular target in this context remains unclear.

\subsubsection{Antrodia cinnamomea (A. cinnamomea) Extract. A.} cinnamomea is a species of fungus commonly used in Asia as a medicinal herb. It possesses a broad range of biological effects, including anti-inflammatory, antioxidant, antifatigue, and antitumor effects [161-163]. A previous study evaluated the effects of orally administered lyophilized extract from the fruit body of $A$. cinnamomea on disease severity in an animal model of imiquimod-induced psoriasis. A. cinnamomea extract reduced psoriasis-like inflammation, infiltration of CD4+ T cells, CD8+ T cells, and neutrophils, and the expression of TNF- $\alpha$, IL-17A, and IL-22 in imiquimod-induced psoriatic skin lesions [164]. Although these observations support a role for A. cinnamomea in the treatment of endosomal TLR-mediated psoriasis inflammation, the effective component mediating these effects and the molecular target of $A$. cinnamomea in this context remain unclear.

7.2. Curcumin. Curcumin is a bright yellow powder obtained from the rhizome of several types of ginger plants. Chemically, curcumin is a diarylheptanoid belonging to the curcuminoid group. It has diverse bioactive effects, including anti-inflammatory, antioxidant, antitumor, and antiatherosclerotic effects [165-167]. Topical use of a curcumin-formulated gel has been shown to inhibit imiquimod-induced psoriasis-like inflammation. Curcumin treatment significantly inhibited imiquimod-induced epidermal hyperplasia and TNF- $\alpha$, IL- $1 \beta$, IL-6, IL17A, IL-17F, and IL-22 production in psoriatic lesions [168]. Curcumin is known to inhibit NF- $\kappa$ B activation by inhibiting $\mathrm{I} \kappa \mathrm{B}$ phosphorylation and degradation. NF- $\kappa \mathrm{B}$ signaling mediates the production of the inflammatory cytokines TNF- $\alpha$, IL- $1 \beta$, IL-6, and IL-23, which cooperatively induce the production of IL-17 cytokines and IL-22 from dermal $\gamma \delta$ T cells. Therefore, curcumin might inhibit endosomal TLR-induced psoriatic inflammation by targeting $\mathrm{NF}-\kappa \mathrm{B}$ signaling. Consistent with this hypothesis, curcumin-mediated inhibition of $\mathrm{NF}-\kappa \mathrm{B}$ activation resulted in the downregulation of IL-17 and IL-22.

7.3. Resveratrol. Resveratrol is a stilbenoid, which is a type of natural phenol found in grapes, berries, and nuts. It possesses anti-inflammatory and antioxidant effects and is used as a dietary supplement $[169,170]$. Oral administration of resveratrol diminished the severity of imiquimod-induced psoriasis-like inflammation in an animal model, and microarray analysis revealed that resveratrol treatment inhibited imiquimod-induced expression of IL-17A, IL-19, and IL23p19. Resveratrol has been shown to inhibit LPS- and TNF- $\alpha$-induced NF- $\kappa$ B activation [171]. Thus, resveratrol might inhibit imiquimod-induced psoriatic inflammation by directly or indirectly targeting signaling of NF- $\kappa \mathrm{B}$.

7.4. Thiostrepton. Thiostrepton, an antibiotic derived from several strains of Streptomycetes, functions as an antagonist of TLR7, TLR8, and TLR9. It was identified using a connectivity map screen for functional analogs of bortezomib. Subsequent studies demonstrated that thiostrepton inhibited TLR7-, TLR8-, and TLR9-mediated NF- $\kappa \mathrm{B}$ activation in a cell-based assay. It also reduced the production of TNF- $\alpha$ and IL-12/23p40 induced by R848 and LL37/RNA complexes (TLR7 and TLR8 ligands) and by CpG-ODN and LL37/DNA complexes (TLR9 ligands) in DCs. This natural antibiotic inhibited imiquimod-induced psoriasis-like inflammation in mice. Specifically, thiostrepton inhibited the accumulation of monocytes and DCs and the expression of TNF- $\alpha$, IL- $1 \beta$, and IL-8 in inflammatory lesions. Thiostrepton uses two mechanisms to block endosomal TLR activation. One mechanism depends on its proteasomal inhibitory activity, similar to the mechanism underlying bortezomib-mediated inhibition of endosomal TLR activation. The other mechanism depends on its ability to inhibit endosomal acidification [172].

7.5. Azithromycin. Similar to thiostrepton, azithromycin is an antibiotic isolated from Streptomycetes. Azithromycin possesses anti-inflammatory and immunomodulatory properties and is used to treat bacterial infections [173, 174]. Azithromycin inhibited imiquimod-induced expression of costimulatory molecules (CD40 and CD80) and cytokines (TNF- $\alpha$, IL-10, IL-12p40, IL-12p70, and IL-23p19) in bone marrowderived DCs (BMDCs), and topical treatment with azithromycin attenuated the severity of imiquimod-induced skin inflammation in an animal model of psoriasis. Azithromycin treatment inhibited keratinocyte hyperproliferation and the accumulation of DCs, CD4+ T cells, and CD8+ T cells in psoriatic lesions. The functional mechanism of azithromycin in this context is similar to that of thiostrepton. Azithromycin inhibited lysosomal acidification and the proteolytic processing of TLR7, thereby blocking imiquimod-induced NF- $\kappa \mathrm{B}$ and IRF7 activation in DCs [175]. In addition, a clinical study demonstrated that long-term oral azithromycin treatment improved PASI score in patients with chronic plaque psoriasis, further confirming the antipsoriatic function of this antibiotic [176].

7.6. Andrographolide. Andrographolide is a labdane diterpenoid isolated from the stem and leaves of Andrographis paniculata. This natural compound possesses anti-inflammatory activity and is currently used as a prescription medicine in China for the treatment of laryngitis, diarrhea, and RA. Intragastric administration of andrographolide alleviated imiquimod-induced psoriasis, but not IL-23-induced psoriasis, in mice. The therapeutic effect was dose-dependent, and treatment with $10 \mathrm{mg} / \mathrm{kg}$ andrographolide was as effective as treatment with $10 \mathrm{mg} / \mathrm{kg}$ etanercept in improving clinical scores in mice with imiquimod-induced psoriasis. Andrographolide inhibited imiquimod-induced expression of the genes encoding CD80, CD86, IL-1 $\beta$, IL-6, and IL-23 in 
TABLE 2: Key points of natural modulator in inhibition of psoriatic skin inflammation.

(1) Less cost

(2) More choice of administration routes

(3) More diverse sources

(4) More diverse chemical structures

(5) More diverse targets in endosomal TLR-mediated inflammatory signaling pathways

(6) More diverse mechanisms to block endosomal TLR-mediated inflammation

BMDCs. Treating BMDCs with andrographolide promoted MyD88 degradation and blocked the recruitment of TRAF6 to form signalsomes. Inhibiting autophagic proteolysis in BMDCs using $\mathrm{NH}_{4} \mathrm{Cl}$ or deleting the gene encoding microtubule-associated protein 1 light chain 3 (MAP1LC3B) abolished andrographolide-induced MyD88 degradation [177]. These findings suggested that andrographolide induces autophagic proteolysis of MyD88, thereby reducing psoriatic inflammation by inhibiting TLR-mediated cytokine production.

\section{Conclusion}

As summarized in Table 2, the studies described in this review indicate that natural products from plants, fungi, and bacteria inhibit the activation of endosomal TLRs via mechanisms that block their functions in the initiation and development of psoriasis. Compared with biological drugs, these natural modulators can be more cost-effective and are administered via different routes. Therefore, they are promising candidate drugs for the treatment of psoriasis, and they might inform the development of multiple treatment options.

\section{Conflicts of Interest}

The authors declare that they have no conflict of interests regarding the publication of this manuscript.

\section{Acknowledgments}

This work was supported in part by the National Health Research Institutes, Taiwan (Grants IM-105-PP-02 and NHRI-EX106-10630SI) and Ministry of Science and Technology of Taiwan (Grants MOST104-3011-B010001, MOST 105-2314-B-400-006, and MOST 105-2320B-400-013-MY3).

\section{References}

[1] M. Lebwohl, "Psoriasis," Lancet, vol. 361, no. 9364, pp. 11971204, 2003.

[2] F. O. Nestle, D. H. Kaplan, and J. Barker, "Psoriasis," The New England Journal of Medicine, vol. 361, no. 5, pp. 496-509, 2009.

[3] G. K. Perera, P. D. Meglio, and F. O. Nestle, "Psoriasis," Annual Review of Pathology, vol. 7, pp. 385-422, 2012.
[4] M. A. Lowes, A. M. Bowcock, and J. G. Krueger, "Pathogenesis and therapy of psoriasis," Nature, vol. 445, no. 7130, pp. 866-873, 2007.

[5] M. A. Lowes, M. Suarez-Farinas, and J. G. Krueger, "Immunology of psoriasis," Annual Review of Immunology, vol. 32, pp. 227-255, 2014.

[6] N. R. Telfer, R. J. Chalmers, K. Whale, and G. Colman, "The role of streptococcal infection in the initiation of guttate psoriasis," Archives of Dermatology, vol. 128, no. 1, pp. 3942, 1992

[7] T. Ito and F. Furukawa, "Psoriasis guttate acuta triggered by varicella zoster virus infection," European Journal of Dermatology, vol. 10, no. 3, pp. 226-227, 2000.

[8] R. W. Eyre and G. G. Krueger, "Response to injury of skin involved and uninvolved with psoriasis, and its relation to disease activity: Koebner and 'reverse' Koebner reactions," The British Journal of Dermatology, vol. 106, no. 2, pp. 153159, 1982.

[9] N. Balato, L. D. Costanzo, C. Patruno, A. Patri, and F. Ayala, "Effect of weather and environmental factors on the clinical course of psoriasis," Occupational and Environmental Medicine, vol. 70, no. 8, p. 600, 2013.

[10] S. J. d. Brouwer, H. v. Middendorp, C. Stormink et al., "The psychophysiological stress response in psoriasis and rheumatoid arthritis," The British Journal of Dermatology, vol. 170, no. 4, pp. 824-831, 2014.

[11] R. C. Trembath, R. L. Clough, J. L. Rosbotham et al., "Identification of a major susceptibility locus on chromosome $6 p$ and evidence for further disease loci revealed by a two stage genome-wide search in psoriasis," Human Molecular Genetics, vol. 6, no. 5, pp. 813-820, 1997.

[12] R. P. Nair, T. Henseler, S. Jenisch et al., "Evidence for two psoriasis susceptibility loci (HLA and 17q) and two novel candidate regions (16q and 20p) by genome-wide scan," Human Molecular Genetics, vol. 6, no. 8, pp. 1349-1356, 1997.

[13] C. D. Veal, F. Capon, M. H. Allen et al., "Family-based analysis using a dense single-nucleotide polymorphismbased map defines genetic variation at PSORS1, the major psoriasis-susceptibility locus," American Journal of Human Genetics, vol. 71, no. 3, pp. 554-564, 2002.

[14] F. Capon, M. Munro, J. Barker, and R. Trembath, "Searching for the major histocompatibility complex psoriasis susceptibility gene," The Journal of Investigative Dermatology, vol. 118, no. 5, pp. 745-751, 2002.

[15] R. P. Nair, P. E. Stuart, I. Nistor et al., "Sequence and haplotype analysis supports HLA-C as the psoriasis susceptibility 1 gene," American Journal of Human Genetics, vol. 78, no. 5, pp. 827-851, 2006.

[16] D. A. Dias, S. Urban, and U. Roessner, "A historical overview of natural products in drug discovery," Metabolites, vol. 2, no. 2, pp. 303-336, 2012.

[17] L. Chen and J. Yu, "Modulation of Toll-like receptor signaling in innate immunity by natural products," International Immunopharmacology, vol. 37, pp. 65-70, 2016.

[18] S. Akira, K. Takeda, and T. Kaisho, "Toll-like receptors: critical proteins linking innate and acquired immunity," Nature Immunology, vol. 2, no. 8, pp. 675-680, 2001.

[19] W. Strober, P. J. Murray, A. Kitani, and T. Watanabe, "Signalling pathways and molecular interactions of NOD1 and NOD2," Nature Reviews. Immunology, vol. 6, no. 1, pp. 9-20, 2006. 
[20] A. Sabbah, T. H. Chang, R. Harnack et al., "Activation of innate immune antiviral responses by Nod2," Nature Immunology, vol. 10, no. 10, pp. 1073-1080, 2009.

[21] H. S. Goodridge, C. N. Reyes, C. A. Becker et al., "Activation of the innate immune receptor Dectin-1 upon formation of a 'phagocytic synapse'," Nature, vol. 472, no. 7344, pp. 471475, 2011.

[22] D. Sancho and C. R. e. Sousa, "Signaling by myeloid C-type lectin receptors in immunity and homeostasis," Annual Review of Immunology, vol. 30, pp. 491-529, 2012.

[23] H. Kato, S. Sato, M. Yoneyama et al., "Cell type-specific involvement of RIG-I in antiviral response," Immunity, vol. 23, no. 1, pp. 19-28, 2005.

[24] M. Yoneyama, M. Kikuchi, T. Natsukawa et al., "The RNA helicase RIG-I has an essential function in double-stranded RNA-induced innate antiviral responses," Nature Immunology, vol. 5, no. 7, pp. 730-737, 2004.

[25] S. Rothenfusser, N. Goutagny, G. DiPerna et al., "The RNA helicase Lgp2 inhibits TLR-independent sensing of viral replication by retinoic acid-inducible gene-I," Journal of Immunology, vol. 175, no. 8, pp. 5260-5268, 2005.

[26] T. Satoh, H. Kato, Y. Kumagai et al., "LGP2 is a positive regulator of RIG-I- and MDA5-mediated antiviral responses," Proceedings of the National Academy of Sciences of the United States of America, vol. 107, no. 4, pp. 1512-1517, 2010.

[27] R. Suresh and D. M. Mosser, "Pattern recognition receptors in innate immunity, host defense, and immunopathology," Advances in Physiology Education, vol. 37, no. 4, pp. 284291, 2013.

[28] S. Tartey and O. Takeuchi, "Pathogen recognition and Tolllike receptor targeted therapeutics in innate immune cells," International Reviews of Immunology, pp. 1-17, 2017.

[29] X. Cao, "Self-regulation and cross-regulation of patternrecognition receptor signalling in health and disease," Nature Reviews. Immunology, vol. 16, no. 1, pp. 35-50, 2016.

[30] F. L. Rock, G. Hardiman, J. C. Timans, R. A. Kastelein, and J. F. Bazan, "A family of human receptors structurally related to Drosophila toll," Proceedings of the National Academy of Sciences of the United States of America, vol. 95, no. 2, pp. 588-593, 1998.

[31] T. H. Chuang and R. J. Ulevitch, "Cloning and characterization of a sub-family of human toll-like receptors: hTLR7, hTLR8 and hTLR9," European Cytokine Network, vol. 11, no. 3, pp. 372-378, 2000.

[32] O. Takeuchi, T. Kawai, H. Sanjo et al., "TLR6: a novel member of an expanding toll-like receptor family," Gene, vol. 231, no. 1-2, pp. 59-65, 1999.

[33] X. Du, A. Poltorak, Y. Wei, and B. Beutler, "Three novel mammalian toll-like receptors: gene structure, expression, and evolution," European Cytokine Network, vol. 11, no. 3, pp. 362-371, 2000.

[34] T. H. Chuang and R. J. Ulevitch, "Identification of hTLR10: a novel human Toll-like receptor preferentially expressed in immune cells," Biochimica et Biophysica Acta, vol. 1518, no. 1-2, pp. 157-161, 2001.

[35] J. L. Imler and J. A. Hoffmann, "Toll receptors in innate immunity," Trends in Cell Biology, vol. 11, no. 7, pp. 304$311,2001$.

[36] T. Kawai and S. Akira, "TLR signaling," Cell Death and Differentiation, vol. 13, no. 5, pp. 816-825, 2006.
[37] F. Leulier and B. Lemaitre, "Toll-like receptors-taking an evolutionary approach," Nature Reviews. Genetics, vol. 9, no. 3, pp. 165-178, 2008.

[38] N. Novak, S. Koch, J. P. Allam, and T. Bieber, "Dendritic cells: bridging innate and adaptive immunity in atopic dermatitis," The Journal of Allergy and Clinical Immunology, vol. 125, no. 1, pp. 50-59, 2010.

[39] K. A. Zarember and P. J. Godowski, “Tissue expression of human Toll-like receptors and differential regulation of Toll-like receptor mRNAs in leukocytes in response to microbes, their products, and cytokines," Journal of Immunology, vol. 168, no. 2, pp. 554-561, 2002.

[40] C. Pasare and R. Medzhitov, "Toll-like receptors: linking innate and adaptive immunity," Advances in Experimental Medicine and Biology, vol. 560, pp. 11-18, 2005.

[41] A. P. West, A. A. Koblansky, and S. Ghosh, "Recognition and signaling by toll-like receptors," Annual Review of Cell and Developmental Biology, vol. 22, pp. 409-437, 2006.

[42] A. O. Aliprantis, R. B. Yang, M. R. Mark et al., "Cell activation and apoptosis by bacterial lipoproteins through toll-like receptor-2," Science, vol. 285, no. 5428, pp. 736739, 1999.

[43] P. S. Coelho, A. Klein, A. Talvani et al., "Glycosylphosphatidylinositol-anchored mucin-like glycoproteins isolated from Trypanosoma cruzi trypomastigotes induce in vivo leukocyte recruitment dependent on $\mathrm{MCP}-1$ production by IFNgamma-primed-macrophages," Journal of Leukocyte Biology, vol. 71, no. 5, pp. 837-844, 2002.

[44] C. A. Janeway Jr. and R. Medzhitov, "Innate immune recognition," Annual Review of Immunology, vol. 20, pp. 197216, 2002.

[45] P. Massari, P. Henneke, Y. Ho, E. Latz, D. T. Golenbock, and L. M. Wetzler, "Cutting edge: immune stimulation by neisserial porins is toll-like receptor 2 and MyD88 dependent," Journal of Immunology, vol. 168, no. 4, pp. 1533-1537, 2002.

[46] T. K. Means, S. Wang, E. Lien, A. Yoshimura, D. T. Golenbock, and M. J. Fenton, "Human toll-like receptors mediate cellular activation by Mycobacterium tuberculosis," Journal of Immunology, vol. 163, no. 7, pp. 3920-3927, 1999.

[47] R. Schwandner, R. Dziarski, H. Wesche, M. Rothe, and C. J. Kirschning, "Peptidoglycan- and lipoteichoic acid-induced cell activation is mediated by toll-like receptor 2," The Journal of Biological Chemistry, vol. 274, no. 25, pp. 17406-17409, 1999.

[48] D. M. Underhill, A. Ozinsky, A. M. Hajjar et al., "The toll-like receptor 2 is recruited to macrophage phagosomes and discriminates between pathogens," Nature, vol. 401, no. 6755, pp. 811-815, 1999.

[49] A. Ozinsky, D. M. Underhill, J. D. Fontenot et al., "The repertoire for pattern recognition of pathogens by the innate immune system is defined by cooperation between toll-like receptors," Proceedings of the National Academy of Sciences of the United States of America, vol. 97, no. 25, pp. 1376613771, 2000.

[50] O. Takeuchi, T. Kawai, P. F. Muhlradt et al., "Discrimination of bacterial lipoproteins by Toll-like receptor 6," International Immunology, vol. 13, no. 7, pp. 933-940, 2001.

[51] O. Takeuchi, S. Sato, T. Horiuchi et al., "Cutting edge: role of Toll-like receptor 1 in mediating immune response to microbial lipoproteins," Journal of Immunology, vol. 169, no. 1, pp. 10-14, 2002. 
[52] A. Poltorak, X. He, I. Smirnova et al., "Defective LPS signaling in $\mathrm{C} 3 \mathrm{H} / \mathrm{HeJ}$ and $\mathrm{C} 57 \mathrm{BL} / 10 \mathrm{ScCr}$ mice: mutations in Tlr4 gene," Science, vol. 282, no. 5396, pp. 2085-2088, 1998.

[53] F. Hayashi, K. D. Smith, A. Ozinsky et al., "The innate immune response to bacterial flagellin is mediated by Tolllike receptor 5," Nature, vol. 410, no. 6832, pp. 1099-1103, 2001.

[54] L. Alexopoulou, A. C. Holt, R. Medzhitov, and R. A. Flavell, "Recognition of double-stranded RNA and activation of NF-kappaB by Toll-like receptor 3," Nature, vol. 413, no. 6857 , pp. 732-738, 2001.

[55] S. S. Diebold, T. Kaisho, H. Hemmi, S. Akira, and C. R. e. Sousa, "Innate antiviral responses by means of TLR7mediated recognition of single-stranded RNA," Science, vol. 303, no. 5663, pp. 1529-1531, 2004.

[56] F. Heil, H. Hemmi, H. Hochrein et al., "Species-specific recognition of single-stranded RNA via toll-like receptor 7 and 8," Science, vol. 303, no. 5663, pp. 1526-1529, 2004.

[57] S. Bauer, C. J. Kirschning, H. Hacker et al., "Human TLR9 confers responsiveness to bacterial DNA via species-specific CpG motif recognition," Proceedings of the National Academy of Sciences of the United States of America, vol. 98, no. 16, pp. 9237-9242, 2001.

[58] H. Hemmi, O. Takeuchi, T. Kawai et al., "A toll-like receptor recognizes bacterial DNA," Nature, vol. 408, no. 6813, pp. 740-745, 2000.

[59] A. M. Krieg, "The role of CpG motifs in innate immunity," Current Opinion in Immunology, vol. 12, no. 1, pp. 35-43, 2000.

[60] A. M. Krieg, A. K. Yi, S. Matson et al., "CpG motifs in bacterial DNA trigger direct B-cell activation," Nature, vol. 374, no. 6522, pp. 546-549, 1995.

[61] P. Matzinger, "The danger model: a renewed sense of self," Science, vol. 296, no. 5566, pp. 301-305, 2002.

[62] S. Y. Seong and P. Matzinger, "Hydrophobicity: an ancient damage-associated molecular pattern that initiates innate immune responses," Nature Reviews. Immunology, vol. 4, no. 6, pp. 469-478, 2004.

[63] J. F. Curtin, N. Liu, M. Candolfi et al., "HMGB1 mediates endogenous TLR2 activation and brain tumor regression," PLoS Medicine, vol. 6, no. 1, p. e10, 2009.

[64] D. Jiang, J. Liang, J. Fan et al., "Regulation of lung injury and repair by toll-like receptors and hyaluronan," Nature Medicine, vol. 11, no. 11, pp. 1173-1179, 2005.

[65] S. Kim, H. Takahashi, W. W. Lin et al., "Carcinoma-produced factors activate myeloid cells through TLR2 to stimulate metastasis," Nature, vol. 457, no. 7225, pp. 102-106, 2009.

[66] R. Liu-Bryan, K. Pritzker, G. S. Firestein, and R. Terkeltaub, "TLR2 signaling in chondrocytes drives calcium pyrophosphate dihydrate and monosodium urate crystal-induced nitric oxide generation," Journal of Immunology, vol. 174, no. 8, pp. 5016-5023, 2005.

[67] R. Liu-Bryan, P. Scott, A. Sydlaske, D. M. Rose, and R. Terkeltaub, "Innate immunity conferred by Toll-like receptors 2 and 4 and myeloid differentiation factor 88 expression is pivotal to monosodium urate monohydrate crystalinduced inflammation," Arthritis and Rheumatism, vol. 52, no. 9, pp. 2936-2946, 2005.

[68] L. Schaefer, A. Babelova, E. Kiss et al., "The matrix component biglycan is proinflammatory and signals through
Toll-like receptors 4 and 2 in macrophages," The Journal of Clinical Investigation, vol. 115, no. 8, pp. 2223-2233, 2005.

[69] R. M. Vabulas, P. Ahmad-Nejad, C. d. Costa et al., "Endocytosed HSP60s use toll-like receptor 2 (TLR2) and TLR4 to activate the toll/interleukin-1 receptor signaling pathway in innate immune cells," The Journal of Biological Chemistry, vol. 276, no. 33, pp. 31332-31339, 2001.

[70] R. M. Vabulas, P. Ahmad-Nejad, S. Ghose, C. J. Kirschning, R. D. Issels, and H. Wagner, "HSP70 as endogenous stimulus of the Toll/interleukin-1 receptor signal pathway," The Journal of Biological Chemistry, vol. 277, no. 17, pp. 1510715112, 2002

[71] R. M. Vabulas, S. Braedel, N. Hilf et al., "The endoplasmic reticulum-resident heat shock protein Gp96 activates dendritic cells via the Toll-like receptor $2 / 4$ pathway," The Journal of Biological Chemistry, vol. 277, no. 23, pp. 2084720853, 2002.

[72] A. Biragyn, P. A. Ruffini, C. A. Leifer et al., "Toll-like receptor 4-dependent activation of dendritic cells by beta-defensin 2," Science, vol. 298, no. 5595, pp. 1025-1029, 2002.

[73] Y. Imai, K. Kuba, G. G. Neely et al., "Identification of oxidative stress and Toll-like receptor 4 signaling as a key pathway of acute lung injury," Cell, vol. 133, no. 2, pp. 235-249, 2008.

[74] G. B. Johnson, G. J. Brunn, Y. Kodaira, and J. L. Platt, "Receptor-mediated monitoring of tissue well-being via detection of soluble heparan sulfate by Toll-like receptor 4," Journal of Immunology, vol. 168, no. 10, pp. 5233-5239, 2002.

[75] K. Midwood, S. Sacre, A. M. Piccinini et al., "Tenascin-C is an endogenous activator of Toll-like receptor 4 that is essential for maintaining inflammation in arthritic joint disease," Nature Medicine, vol. 15, no. 7, pp. 774-780, 2009.

[76] Y. Okamura, M. Watari, E. S. Jerud et al., "The extra domain A of fibronectin activates Toll-like receptor 4," The Journal of Biological Chemistry, vol. 276, no. 13, pp. 10229-10233, 2001.

[77] J. S. Park, D. Svetkauskaite, Q. He et al., "Involvement of tolllike receptors 2 and 4 in cellular activation by high mobility group box 1 protein," The Journal of Biological Chemistry, vol. 279, no. 9, pp. 7370-7377, 2004.

[78] S. T. Smiley, J. A. King, and W. W. Hancock, "Fibrinogen stimulates macrophage chemokine secretion through tolllike receptor 4," Journal of Immunology, vol. 167, no. 5, pp. 2887-2894, 2001.

[79] B. M. Tesar, D. Jiang, J. Liang, S. M. Palmer, P. W. Noble, and D. R. Goldstein, "The role of hyaluronan degradation products as innate alloimmune agonists," American Journal of Transplantation, vol. 6, no. 11, pp. 2622-2635, 2006.

[80] F. J. Barrat, T. Meeker, J. Gregorio et al., "Nucleic acids of mammalian origin can act as endogenous ligands for tolllike receptors and may promote systemic lupus erythematosus," The Journal of Experimental Medicine, vol. 202, no. 8, pp. 1131-1139, 2005.

[81] K. Kariko, H. Ni, J. Capodici, M. Lamphier, and D. Weissman, "mRNA is an endogenous ligand for Toll-like receptor 3," The Journal of Biological Chemistry, vol. 279, no. 13, pp. 12542-12550, 2004.

[82] E. A. Leadbetter, I. R. Rifkin, A. M. Hohlbaum, B. C. Beaudette, M. J. Shlomchik, and A. Marshak-Rothstein, "Chromatin-IgG complexes activate B cells by dual engagement of IgM and Toll-like receptors," Nature, vol. 416, no. 6881, pp. 603-607, 2002. 
[83] J. Vollmer, S. Tluk, C. Schmitz et al., "Immune stimulation mediated by autoantigen binding sites within small nuclear RNAs involves toll-like receptors 7 and 8," The Journal of Experimental Medicine, vol. 202, no. 11, pp. 1575-1585, 2005.

[84] L. A. O'Neill and A. G. Bowie, "The family of five: TIRdomain-containing adaptors in toll-like receptor signalling," Nature Reviews. Immunology, vol. 7, no. 5, pp. 353-364, 2007.

[85] T. Kawai and S. Akira, "TLR signaling," Seminars in Immunology, vol. 19, no. 1, pp. 24-32, 2007.

[86] K. A. Fitzgerald, D. C. Rowe, B. J. Barnes et al., "LPS-TLR4 signaling to IRF-3/7 and NF-kappaB involves the toll adapters TRAM and TRIF," The Journal of Experimental Medicine, vol. 198, no. 7, pp. 1043-1055, 2003.

[87] E. Meylan, K. Burns, K. Hofmann et al., "RIP1 is an essential mediator of Toll-like receptor 3-induced NF-kappa B activation," Nature Immunology, vol. 5, no. 5, pp. 503-507, 2004.

[88] M. S. Lee and Y. J. Kim, "Signaling pathways downstream of pattern-recognition receptors and their cross talk," Annual Review of Biochemistry, vol. 76, pp. 447-480, 2007.

[89] A. L. Blasius and B. Beutler, "Intracellular toll-like receptors," Immunity, vol. 32, no. 3, pp. 305-315, 2010.

[90] A. F. McGettrick and L. A. O'Neill, "Localisation and trafficking of Toll-like receptors: an important mode of regulation," Current Opinion in Immunology, vol. 22, no. 1, pp. 20-27, 2010.

[91] J. Liu, C. Xu, L. C. Hsu, Y. Luo, R. Xiang, and T. H. Chuang, "A five-amino-acid motif in the undefined region of the TLR8 ectodomain is required for species-specific ligand recognition," Molecular Immunology, vol. 47, no. 5, pp. 1083-1090, 2010.

[92] C. Y. Lai, Y. L. Liu, G. Y. Yu et al., "TLR7/8 agonists activate a mild immune response in rabbits through TLR8 but not TLR7," Vaccine, vol. 32, no. 43, pp. 5593-5599, 2014.

[93] B. L. Lee, J. E. Moon, J. H. Shu et al., "UNC93B1 mediates differential trafficking of endosomal TLRs," eLife, vol. 2, article e00291, 2013.

[94] Y. M. Kim, M. M. Brinkmann, M. E. Paquet, and H. L. Ploegh, "UNC93B1 delivers nucleotide-sensing toll-like receptors to endolysosomes," Nature, vol. 452, no. 7184, pp. 234-238, 2008.

[95] B. L. Lee and G. M. Barton, "Trafficking of endosomal Tolllike receptors," Trends in Cell Biology, vol. 24, no. 6, pp. 360-369, 2014.

[96] A. M. Avalos, O. Kirak, J. M. Oelkers et al., "Cell-specific TLR9 trafficking in primary APCs of transgenic TLR9-GFP mice," Journal of Immunology, vol. 190, no. 2, pp. 695-702, 2013.

[97] A. Garcia-Cattaneo, F. X. Gobert, M. Muller et al., "Cleavage of toll-like receptor 3 by cathepsins $\mathrm{B}$ and $\mathrm{H}$ is essential for signaling," Proceedings of the National Academy of Sciences of the United States of America, vol. 109, no. 23, pp. 90539058,2012

[98] S. E. Ewald, A. Engel, J. Lee, M. Wang, M. Bogyo, and G. M. Barton, "Nucleic acid recognition by toll-like receptors is coupled to stepwise processing by cathepsins and asparagine endopeptidase," The Journal of Experimental Medicine, vol. 208, no. 4, pp. 643-651, 2011.

[99] F. E. Sepulveda, S. Maschalidi, R. Colisson et al., "Critical role for asparagine endopeptidase in endocytic Toll-like receptor signaling in dendritic cells," Immunity, vol. 31, no. 5, pp. 737-748, 2009.
[100] B. Park, M. M. Brinkmann, E. Spooner, C. C. Lee, Y. M. Kim, and H. L. Ploegh, "Proteolytic cleavage in an endolysosomal compartment is required for activation of Toll-like receptor 9," Nature Immunology, vol. 9, no. 12, pp. 1407-1414, 2008.

[101] S. E. Ewald, B. L. Lee, L. Lau et al., "The ectodomain of Tolllike receptor 9 is cleaved to generate a functional receptor," Nature, vol. 456, no. 7222, pp. 658-662, 2008.

[102] M. Onji, A. Kanno, S. Saitoh et al., "An essential role for the N-terminal fragment of toll-like receptor 9 in DNA sensing," Nature Communications, vol. 4, p. 1949, 2013.

[103] Y. Li, I. C. Berke, and Y. Modis, "DNA binding to proteolytically activated TLR9 is sequence-independent and enhanced by DNA curvature," The EMBO Journal, vol. 31, no. 4, pp. 919-931, 2012.

[104] D. Ganguly, G. Chamilos, R. Lande et al., "Self-RNA-antimicrobial peptide complexes activate human dendritic cells through TLR7 and TLR8," The Journal of Experimental Medicine, vol. 206, no. 9, pp. 1983-1994, 2009.

[105] S. Morizane, K. Yamasaki, B. Muhleisen et al., "Cathelicidin antimicrobial peptide LL-37 in psoriasis enables keratinocyte reactivity against TLR9 ligands," The Journal of Investigative Dermatology, vol. 132, no. 1, pp. 135-143, 2012.

[106] G. Chamilos, J. Gregorio, S. Meller et al., "Cytosolic sensing of extracellular self-DNA transported into monocytes by the antimicrobial peptide LL37," Blood, vol. 120, no. 18, pp. 3699-3707, 2012.

[107] D. Yang, Q. Chen, H. Yang, K. J. Tracey, M. Bustin, and J. J. Oppenheim, "High mobility group box-1 protein induces the migration and activation of human dendritic cells and acts as an alarmin," Journal of Leukocyte Biology, vol. 81, no. 1, pp. 59-66, 2007.

[108] E. Brencicova and S. S. Diebold, "Nucleic acids and endosomal pattern recognition: how to tell friend from foe?" Frontiers in Cellular and Infection Microbiology, vol. 3, p. 37, 2013.

[109] R. Lande, J. Gregorio, V. Facchinetti et al., "Plasmacytoid dendritic cells sense self-DNA coupled with antimicrobial peptide," Nature, vol. 449, no. 7162, pp. 564-569, 2007.

[110] M. Gilliet and R. Lande, "Antimicrobial peptides and selfDNA in autoimmune skin inflammation," Current Opinion in Immunology, vol. 20, no. 4, pp. 401-407, 2008.

[111] A. Iwasaki and R. Medzhitov, "Toll-like receptor control of the adaptive immune responses," Nature Immunology, vol. 5, no. 10, pp. 987-995, 2004.

[112] F. C. Eberle, J. Bruck, J. Holstein, K. Hirahara, and K. Ghoreschi, "Recent advances in understanding psoriasis," F1000Res, vol. 5, 2016.

[113] S. K. Mahil, F. Capon, and J. N. Barker, "Update on psoriasis immunopathogenesis and targeted immunotherapy," Seminars in Immunopathology, vol. 38, no. 1, pp. 11-27, 2016.

[114] L. v. d. Fits, S. Mourits, J. S. Voerman et al., "Imiquimodinduced psoriasis-like skin inflammation in mice is mediated via the IL-23/IL-17 axis," Journal of Immunology, vol. 182, no. 9, pp. 5836-5845, 2009.

[115] B. Flutter and F. O. Nestle, "TLRs to cytokines: mechanistic insights from the imiquimod mouse model of psoriasis," European Journal of Immunology, vol. 43, no. 12, pp. 31383146, 2013.

[116] U. Patel, N. M. Mark, B. C. Machler, and V. J. Levine, "Imiquimod 5\% cream induced psoriasis: a case report, summary of the literature and mechanism," The British Journal of Dermatology, vol. 164, no. 3, pp. 670-672, 2011. 
[117] M. Gilliet, C. Conrad, M. Geiges et al., "Psoriasis triggered by toll-like receptor 7 agonist imiquimod in the presence of dermal plasmacytoid dendritic cell precursors," Archives of Dermatology, vol. 140, no. 12, pp. 1490-1495, 2004.

[118] P. A. Fanti, E. Dika, S. Vaccari, C. Miscial, and C. Varotti, "Generalized psoriasis induced by topical treatment of actinic keratosis with imiquimod," International Journal of Dermatology, vol. 45, no. 12, pp. 1464-1465, 2006.

[119] M. Suarez-Farinas, R. Arbeit, W. Jiang, F. S. Ortenzio, T. Sullivan, and J. G. Krueger, "Suppression of molecular inflammatory pathways by Toll-like receptor 7,8 , and 9 antagonists in a model of IL-23-induced skin inflammation," PloS One, vol. 8, no. 12, article e84634, 2013.

[120] D. M. Balak, M. B. v. Doorn, R. D. Arbeit et al., "IMO-8400, a toll-like receptor 7, 8 , and 9 antagonist, demonstrates clinical activity in a phase $2 \mathrm{a}$, randomized, placebo-controlled trial in patients with moderate-to-severe plaque psoriasis," Clinical Immunology, vol. 174, pp. 63-72, 2016.

[121] C. Leonardi, K. Papp, B. Strober et al., "The long-term safety of adalimumab treatment in moderate to severe psoriasis: a comprehensive analysis of all adalimumab exposure in all clinical trials," American Journal of Clinical Dermatology, vol. 12, no. 5, pp. 321-337, 2011.

[122] G. R. Burmester, R. Panaccione, K. B. Gordon, M. J. Mcllraith, and A. P. Lacerda, "Adalimumab: long-term safety in 23458 patients from global clinical trials in rheumatoid arthritis, juvenile idiopathic arthritis, ankylosing spondylitis, psoriatic arthritis, psoriasis and Crohn's disease," Annals of the Rheumatic Diseases, vol. 72, no. 4, pp. 517524, 2013.

[123] C. B. Burness and K. McKeage, "Adalimumab: a review in chronic plaque psoriasis,” Drugs, vol. 75, no. 18, pp. 21192130, 2015.

[124] P. J. Mease, B. S. Goffe, J. Metz, A. VanderStoep, B. Finck, and D. J. Burge, "Etanercept in the treatment of psoriatic arthritis and psoriasis: a randomised trial," Lancet, vol. 356, no. 9227, pp. 385-390, 2000.

[125] C. L. Leonardi, J. L. Powers, R. T. Matheson et al., "Etanercept as monotherapy in patients with psoriasis," The New England Journal of Medicine, vol. 349, no. 21, pp. 20142022, 2003.

[126] A. Romero-Mate, C. Garcia-Donoso, and S. CordobaGuijarro, "Efficacy and safety of etanercept in psoriasis/ psoriatic arthritis: an updated review," American Journal of Clinical Dermatology, vol. 8, no. 3, pp. 143-155, 2007.

[127] E. d. Eusebio, J. C. Armario-Hita, and V. A. d. Miquel, "Treatment of psoriasis: focus on clinic-based management with infliximab," American Journal of Clinical Dermatology, vol. 15, Supplement 1, pp. S5-16, 2014.

[128] C. E. Kleyn and C. E. Griffiths, "Infliximab for the treatment of psoriasis," Expert Opinion on Biological Therapy, vol. 6, no. 8, pp. 797-805, 2006.

[129] C. H. Smith, K. Jackson, S. J. Bashir et al., "Infliximab for severe, treatment-resistant psoriasis: a prospective, openlabel study," The British Journal of Dermatology, vol. 155, no. 1, pp. 160-169, 2006.

[130] B. L. Bartlett and S. K. Tyring, "Ustekinumab for chronic plaque psoriasis," Lancet, vol. 371, no. 9625, pp. 1639-1640, 2008.

[131] C. Schmidt, "Ustekinumab poised to enter the psoriasis market," Nature Biotechnology, vol. 26, no. 12, pp. 13171318, 2008.
[132] J. Zweegers, J. M. Groenewoud, J. M. v. d. Reek et al., “Comparison of the one and 5-years effectiveness of adalimumab, etanercept and ustekinumab in psoriasis patients in daily clinical practice: results from the prospective BioCAPTURE registry," The British Journal of Dermatology, vol. 176, no. 4, 2016.

[133] A. Kuhn and T. A. Luger, "Psoriasis: is ustekinumab superior to etanercept for psoriasis?" Nature Reviews. Rheumatology, vol. 6 , no. 9, pp. 500-501, 2010.

[134] F. J. Barrat, T. Meeker, J. H. Chan, C. Guiducci, and R. L. Coffman, "Treatment of lupus-prone mice with a dual inhibitor of TLR7 and TLR9 leads to reduction of autoantibody production and amelioration of disease symptoms," European Journal of Immunology, vol. 37, no. 12, pp. 3582-3586, 2007.

[135] C. Guiducci, C. Tripodo, M. Gong et al., "Autoimmune skin inflammation is dependent on plasmacytoid dendritic cell activation by nucleic acids via TLR7 and TLR9," The Journal of Experimental Medicine, vol. 207, no. 13, pp. 2931-2942, 2010.

[136] F. Rommler, M. Hammel, A. Waldhuber et al., "Guaninemodified inhibitory oligonucleotides efficiently impair TLR7- and TLR9-mediated immune responses of human immune cells," PloS One, vol. 10, no. 2, article e0116703, 2015.

[137] J. Li, X. Wang, F. Zhang, and H. Yin, "Toll-like receptors as therapeutic targets for autoimmune connective tissue diseases," Pharmacology \& Therapeutics, vol. 138, no. 3, pp. 441-451, 2013.

[138] T. Parkinson, "The future of toll-like receptor therapeutics," Current Opinion in Molecular Therapeutics, vol. 10, no. 1, pp. 21-31, 2008.

[139] A. Thanou and J. T. Merrill, "Treatment of systemic lupus erythematosus: new therapeutic avenues and blind alleys," Nature Reviews. Rheumatology, vol. 10, no. 1, pp. 23-34, 2014.

[140] A. Kuznik, M. Bencina, U. Svajger, M. Jeras, B. Rozman, and R. Jerala, "Mechanism of endosomal TLR inhibition by antimalarial drugs and imidazoquinolines," Journal of Immunology, vol. 186, no. 8, pp. 4794-4804, 2011.

[141] S. Kalia and J. P. Dutz, "New concepts in antimalarial use and mode of action in dermatology," Dermatologic Therapy, vol. 20, no. 4, pp. 160-174, 2007.

[142] T. C. Kouroukis, F. G. Baldassarre, A. E. Haynes, K. Imrie, D. E. Reece, and M. C. Cheung, "Bortezomib in multiple myeloma: systematic review and clinical considerations," Current Oncology, vol. 21, no. 4, pp. e573-e603, 2014.

[143] Z. Skrott and B. Cvek, "Linking the activity of bortezomib in multiple myeloma and autoimmune diseases," Critical Reviews in Oncology/Hematology, vol. 92, no. 2, pp. 61-70, 2014.

[144] A. Fierabracci, "Proteasome inhibitors: a new perspective for treating autoimmune diseases," Current Drug Targets, vol. 13, no. 13, pp. 1665-1675, 2012.

[145] M. Hirai, N. Kadowaki, T. Kitawaki et al., "Bortezomib suppresses function and survival of plasmacytoid dendritic cells by targeting intracellular trafficking of Toll-like receptors and endoplasmic reticulum homeostasis," Blood, vol. 117, no. 2, pp. 500-509, 2011.

[146] H. T. Ichikawa, T. Conley, T. Muchamuel et al., "Beneficial effect of novel proteasome inhibitors in murine lupus via dual inhibition of type I interferon and autoantibody-secreting 
cells," Arthritis and Rheumatism, vol. 64, no. 2, pp. 493-503, 2012.

[147] L. F. Hou, S. J. He, X. Li et al., "Oral administration of artemisinin analog SM934 ameliorates lupus syndromes in MRL/lpr mice by inhibiting Th1 and Th17 cell responses," Arthritis and Rheumatism, vol. 63, no. 8, pp. 2445-2455, 2011.

[148] L. F. Hou, S. J. He, X. Li et al., "SM934 treated lupus-prone NZB $x$ NZW F1 mice by enhancing macrophage interleukin-10 production and suppressing pathogenic $\mathrm{T}$ cell development," PloS One, vol. 7, no. 2, article e32424, 2012.

[149] Y. Wu, S. He, B. Bai et al., "Therapeutic effects of the artemisinin analog SM934 on lupus-prone MRL/lpr mice via inhibition of TLR-triggered B-cell activation and plasma cell formation," Cellular \& Molecular Immunology, vol. 13, no. 3, pp. 379-390, 2016.

[150] R. Hernanz, S. Martinez-Revelles, R. Palacios et al., "Toll-like receptor 4 contributes to vascular remodelling and endothelial dysfunction in angiotensin II-induced hypertension," British Journal of Pharmacology, vol. 172, no. 12, pp. 31593176, 2015.

[151] F. Capolunghi, M. M. Rosado, S. Cascioli et al., "Pharmacological inhibition of TLR9 activation blocks autoantibody production in human B cells from SLE patients," Rheumatology (Oxford), vol. 49, no. 12, pp. 2281-2289, 2010.

[152] M. Kondo, A. Tahara, K. Hayashi et al., "Renoprotective effects of novel interleukin-1 receptor-associated kinase 4 inhibitor AS2444697 through anti-inflammatory action in 5/6 nephrectomized rats," Naunyn-Schmiedeberg's Archives of Pharmacology, vol. 387, no. 10, pp. 909-919, 2014.

[153] Y. W. Wu, W. Tang, and J. P. Zuo, “Toll-like receptors: potential targets for lupus treatment," Acta Pharmacologica Sinica, vol. 36, no. 12, pp. 1395-1407, 2015.

[154] L. Schopf, A. Savinainen, K. Anderson et al., "IKKbeta inhibition protects against bone and cartilage destruction in a rat model of rheumatoid arthritis," Arthritis and Rheumatism, vol. 54, no. 10, pp. 3163-3173, 2006.

[155] K. Nagashima, V. G. Sasseville, D. Wen et al., "Rapid TNFR1dependent lymphocyte depletion in vivo with a selective chemical inhibitor of IKKbeta," Blood, vol. 107, no. 11, pp. 4266-4273, 2006.

[156] G. Mbalaviele, C. D. Sommers, S. L. Bonar et al., “A novel, highly selective, tight binding IkappaB kinase-2 (IKK-2) inhibitor: a tool to correlate IKK-2 activity to the fate and functions of the components of the nuclear factor-kappaB pathway in arthritis-relevant cells and animal models," The Journal of Pharmacology and Experimental Therapeutics, vol. 329, no. 1, pp. 14-25, 2009.

[157] P. C. v. d. Kerkhof, "Update on retinoid therapy of psoriasis in: an update on the use of retinoids in dermatology," Dermatologic Therapy, vol. 19, no. 5, pp. 252-263, 2006.

[158] L. Kowalzick, "Clinical experience with topical calcitriol (1,25-dihydroxyvitamin D3) in psoriasis," The British Journal of Dermatology, vol. 144, Supplement 58, pp. 21-25, 2001.

[159] H. Yuan, M. Zhu, W. Guo et al., "Mustard seeds (Sinapis alba Linn) attenuate azoxymethane-induced colon carcinogenesis," Redox Report, vol. 16, no. 1, pp. 38-44, 2011.

[160] R. Yang, Q. Zhou, C. Wen et al., "Mustard seed (Sinapis alba Linn) attenuates imiquimod-induced psoriasiform inflammation of BALB/c mice," The Journal of Dermatology, vol. 40, no. 7, pp. 543-552, 2013.
[161] T. T. Huang, S. P. Wu, K. Y. Chong et al., "The medicinal fungus Antrodia cinnamomea suppresses inflammation by inhibiting the NLRP3 inflammasome," Journal of Ethnopharmacology, vol. 155, no. 1, pp. 154-164, 2014.

[162] F. C. Liu, M. T. Lai, Y. Y. Chen et al., "Elucidating the inhibitory mechanisms of the ethanolic extract of the fruiting body of the mushroom Antrodia cinnamomea on the proliferation and migration of murine leukemia WEHI-3 cells and their tumorigenicity in a BALB/c allograft tumor model," Phytomedicine, vol. 20, no. 10, pp. 874-882, 2013.

[163] M. D. Wu, M. J. Cheng, W. Y. Wang et al., “Antioxidant activities of extracts and metabolites isolated from the fungus Antrodia cinnamomea," Natural Product Research, vol. 25, no. 16, pp. 1488-1496, 2011.

[164] M. H. Li, H. C. Wu, H. J. Yao, C. C. Lin, S. F. Wen, and I. H. Pan, "Antrodia cinnamomea extract inhibits Th17 cell differentiation and ameliorates imiquimod-induced psoriasiform skin inflammation," The American Journal of Chinese Medicine, vol. 43, no. 7, pp. 1401-1417, 2015.

[165] J. W. Cho, K. S. Lee, and C. W. Kim, "Curcumin attenuates the expression of IL-1beta, IL- 6 , and TNF-alpha as well as cyclin E in TNF-alpha-treated HaCaT cells; NF-kappaB and MAPKs as potential upstream targets," International Journal of Molecular Medicine, vol. 19, no. 3, pp. 469-474, 2007.

[166] A. C. Bharti, N. Donato, and B. B. Aggarwal, "Curcumin (diferuloylmethane) inhibits constitutive and IL-6-inducible STAT3 phosphorylation in human multiple myeloma cells," Journal of Immunology, vol. 171, no. 7, pp. 3863-3871, 2003.

[167] A. R. Hussain, M. Ahmed, N. A. Al-Jomah et al., "Curcumin suppresses constitutive activation of nuclear factor-kappa B and requires functional Bax to induce apoptosis in Burkitt's lymphoma cell lines," Molecular Cancer Therapeutics, vol. 7, no. 10, pp. 3318-3329, 2008.

[168] J. Sun, Y. Zhao, and J. Hu, "Curcumin inhibits imiquimodinduced psoriasis-like inflammation by inhibiting IL-1beta and IL-6 production in mice," PloS One, vol. 8, no. 6, article e67078, 2013.

[169] K. B. Cullberg, J. Olholm, S. K. Paulsen et al., "Resveratrol has inhibitory effects on the hypoxia-induced inflammation and angiogenesis in human adipose tissue in vitro," European Journal of Pharmaceutical Sciences, vol. 49, no. 2, pp. 251$257,2013$.

[170] J. Olholm, S. K. Paulsen, K. B. Cullberg, B. Richelsen, and S. B. Pedersen, "Anti-inflammatory effect of resveratrol on adipokine expression and secretion in human adipose tissue explants," International Journal of Obesity, vol. 34, no. 10, pp. 1546-1553, 2010.

[171] T. N. Kjaer, K. Thorsen, N. Jessen, K. Stenderup, and S. B. Pedersen, "Resveratrol ameliorates imiquimod-induced psoriasis-like skin inflammation in mice," PloS One, vol. 10, no. 5, article e0126599, 2015.

[172] C. Y. Lai, D. W. Yeh, C. H. Lu et al., "Identification of thiostrepton as a novel inhibitor for psoriasis-like inflammation induced by TLR7-9," Journal of Immunology, vol. 195, no. 8, pp. 3912-3921, 2015.

[173] M. Bosnar, B. Bosnjak, S. Cuzic et al., "Azithromycin and clarithromycin inhibit lipopolysaccharide-induced murine pulmonary neutrophilia mainly through effects on macrophage-derived granulocyte-macrophage colonystimulating factor and interleukin-1beta," The Journal of Pharmacology and Experimental Therapeutics, vol. 331, no. 1, pp. 104-113, 2009. 
[174] V. Ivetic Tkalcevic, B. Bosnjak, B. Hrvacic et al., "Antiinflammatory activity of azithromycin attenuates the effects of lipopolysaccharide administration in mice," European Journal of Pharmacology, vol. 539, no. 1-2, pp. 131-138, 2006.

[175] S. W. Huang, Y. J. Chen, S. T. Wang et al., “Azithromycin impairs TLR7 signaling in dendritic cells and improves the severity of imiquimod-induced psoriasis-like skin inflammation in mice," Journal of Dermatological Science, vol. 84, no. 1, pp. 59-70, 2016.

[176] V. N. Saxena and J. Dogra, "Long-term oral azithromycin in chronic plaque psoriasis: a controlled trial," European Journal of Dermatology, vol. 20, no. 3, pp. 329-333, 2010.

[177] F. Shao, T. Tan, Y. Tan, Y. Sun, X. Wu, and Q. Xu, “Andrographolide alleviates imiquimod-induced psoriasis in mice via inducing autophagic proteolysis of MyD88," Biochemical Pharmacology, vol. 115, pp. 94-103, 2016. 


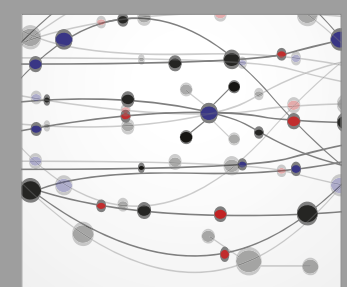

The Scientific World Journal
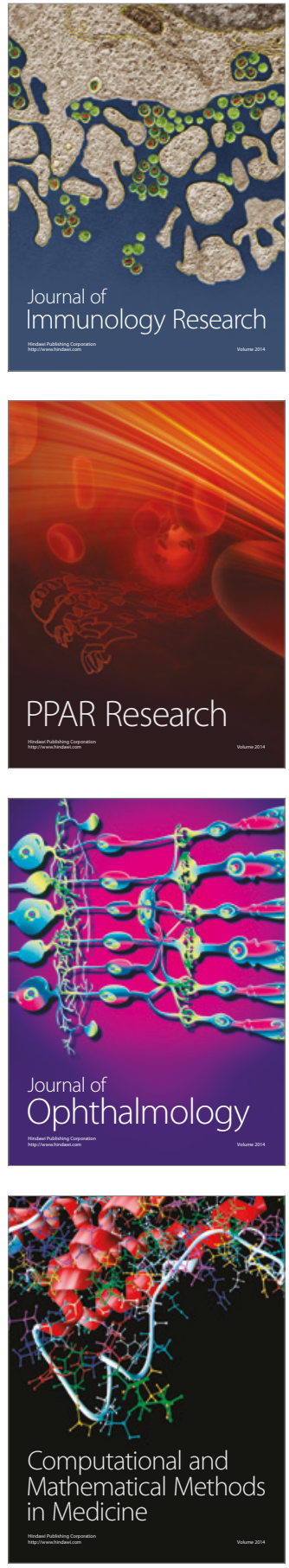

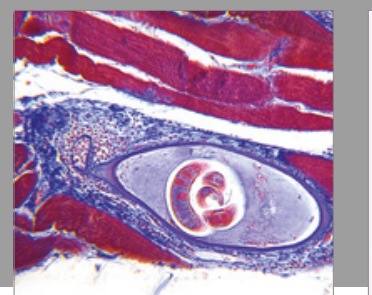

Gastroenterology Research and Practice
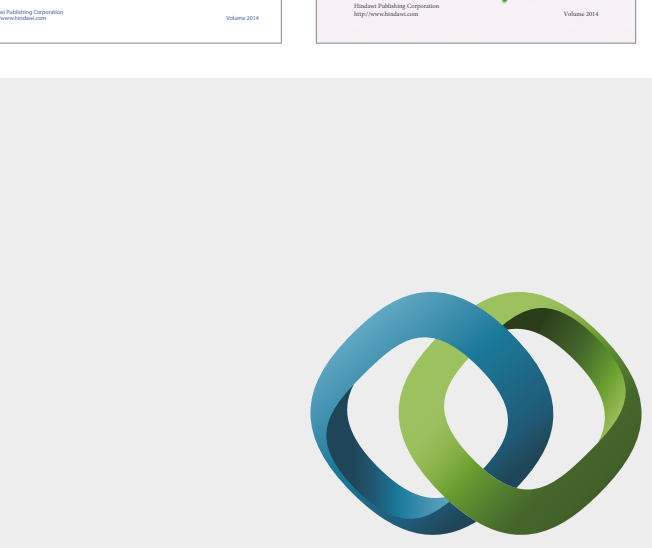

\section{Hindawi}

Submit your manuscripts at

https://www.hindawi.com
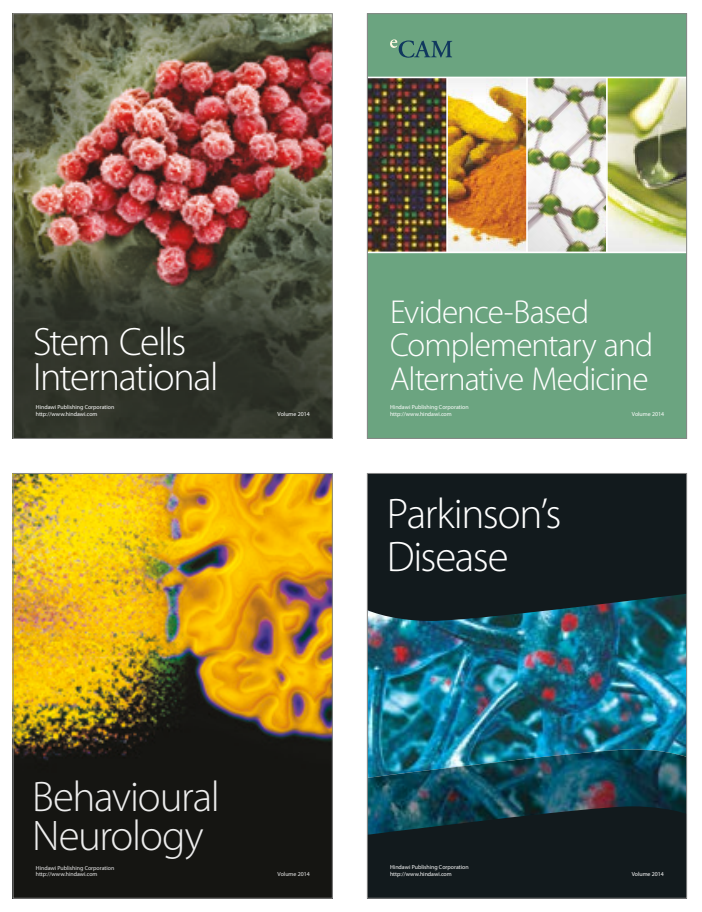
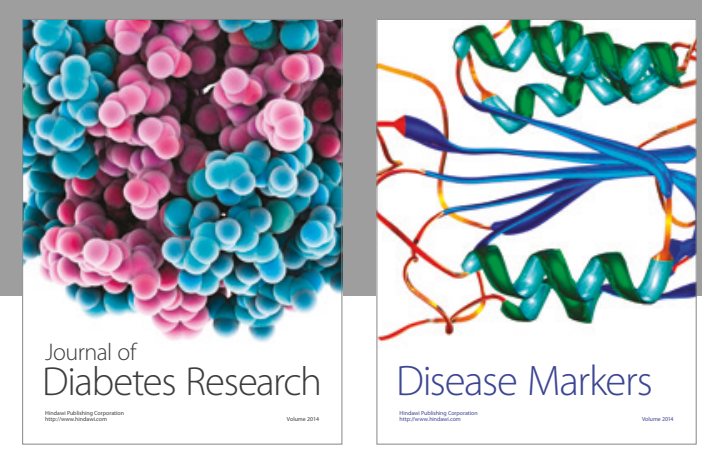

Disease Markers
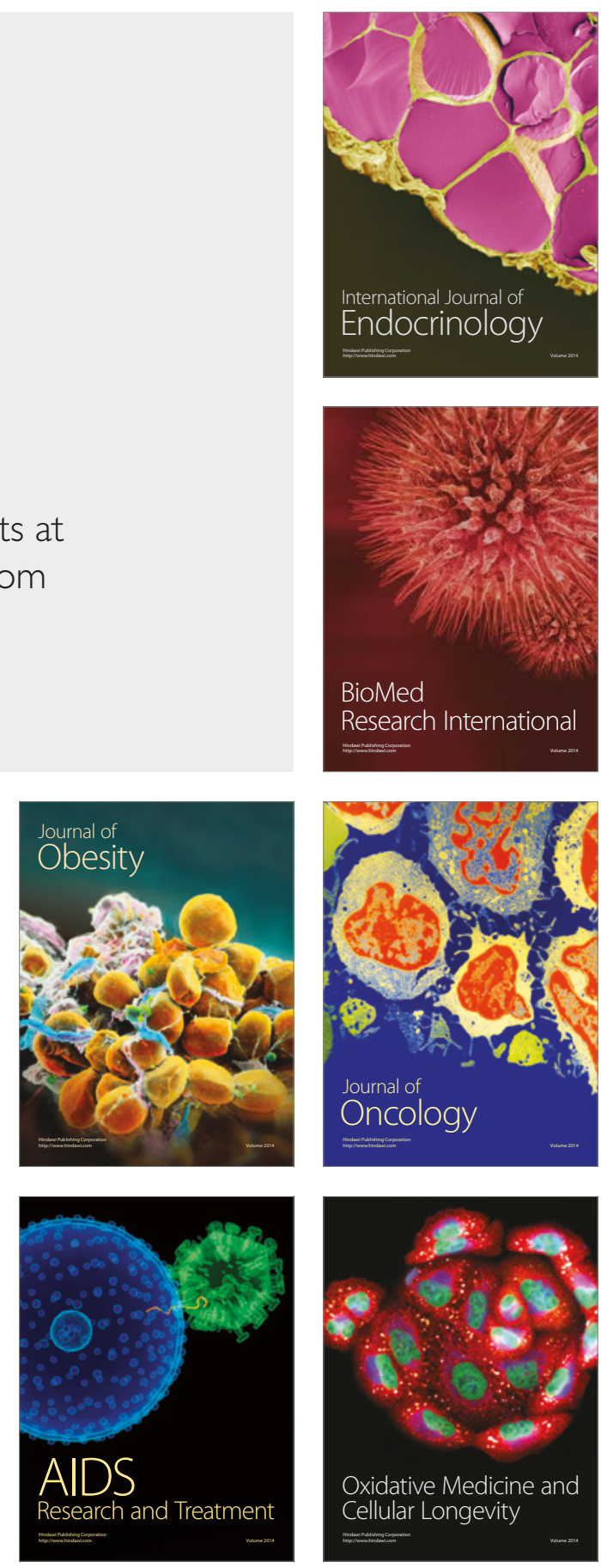